\title{
Response of the HadGEM2 Earth System Model to Future Greenhouse Gas Emissions Pathways to the Year 2300*
}

\author{
John CAesar, Erika Palin, Spencer Liddicoat, Jason Lowe, Eleanor Burke, \\ AnNe PARDAEns, Michael SANDERson, AND Ron KaHANa \\ Met Office Hadley Centre, Exeter, United Kingdom
}

(Manuscript received 31 July 2012, in final form 22 October 2012)

\begin{abstract}
A new ensemble of simulations from the Earth System configuration of the Hadley Centre Global Environmental Model, version 2 (HadGEM2-ES), is used to evaluate the response to historical and projected future greenhouse gas forcings that follow Representative Concentration Pathways (RCPs). In addition to the projected changes during the twenty-first century, extended simulations to the year 2300 allow an investigation into inertia in the climate system post-2100 that may occur even if atmospheric $\mathrm{CO}_{2}$ concentrations have stabilized. Projections of temperature, precipitation, sea level, permafrost, heat waves, and compatible carbon emissions are analyzed. The low emissions scenario RCP 2.6 is the only scenario considered here that is approximately consistent with a $2^{\circ} \mathrm{C}$ global warming limit, though there are regions where local changes in temperature are projected to considerably exceed $2^{\circ} \mathrm{C}$, particularly over northern high-latitude areas. An aggressive mitigation approach, represented here by RCP2.6, could contribute to avoiding the larger-magnitude future climate changes projected under higher emissions scenarios. Despite these benefits, changes should still be expected under an aggressive mitigation pathway and may require adaptation.
\end{abstract}

\section{Introduction}

To avoid the most serious impacts of climate change, the parties to the United Nations Framework Convention on Climate Change (UNFCCC) have agreed to work toward limiting global temperature rise to a maximum of $2^{\circ} \mathrm{C}$ above preindustrial levels (UNFCCC 2011). Research continues into feasible greenhouse gas emissions pathways that could enable this target to be met and the implications for the climate system and related impacts.

A number of studies have begun to assess projected outcomes of a selection of greenhouse gas mitigation scenarios using general circulation models (GCMs). Washington et al. (2009) used the Community Climate System Model, version 3.0 (CCSM3.0), with a low emissions scenario, which stabilizes atmospheric $\mathrm{CO}_{2}$ at

\footnotetext{
* Supplemental information related to this paper is available at the Journals Online website: http://dx.doi.org/10.1175/JCLI-D-1200577.s1.

Corresponding author address: Dr. John Caesar, Met Office Hadley Centre, FitzRoy Road, Exeter EX1 3PB, United Kingdom. E-mail: john.caesar@metoffice.gov.uk
}

around $450 \mathrm{ppm}$ by the year 2100 . The projected global mean temperature increase remained below the $2^{\circ} \mathrm{C}$ level, and they found that about half of the change in temperature and precipitation is avoided, which would otherwise have occurred under a nonmitigation scenario with no explicit climate change intervention policy. Mitigation also resulted in lower projected increases in the rate of sea level rise (caused by thermal expansion), smaller reductions in permafrost area, and a reduced incidence of heat waves. Using the CCSM4.0 model, Meehl et al. (2012) assessed results using the Representative Concentration Pathway 2.6 (RCP2.6) scenario (van Vuuren et al. 2011), which is the low emissions pathway from the set of Representative Concentration Pathways (RCPs) (Moss et al. 2010). In CCSM4.0, the $\mathrm{RCP} 2.6$ pathway resulted in projected global average temperature remaining at less than $2^{\circ} \mathrm{C}$ above the preindustrial level by 2100. Johns et al. (2011) used the E1 aggressive mitigation scenario, outlined in Lowe et al. (2009), to assess changes in a multimodel ensemble and found that twenty-first-century global warming is projected to stay below $2^{\circ} \mathrm{C}$ in 6 of the 10 models evaluated. The E1 scenario has a peak in the atmospheric $\mathrm{CO}_{2}$ equivalent concentration at around $535 \mathrm{ppm}$ in 2045 before stabilizing at around $450 \mathrm{ppm}$ during the twenty-second 
century. However, Arora et al. (2011), using the secondgeneration Canadian Earth System Model (CanESM2) driven by RCP2.6, found a simulated global average warming of $2.3^{\circ} \mathrm{C}$ over the $1850-2100$ period and suggest that being able to limit warming to below $2^{\circ} \mathrm{C}$ by the end of this century may not be feasible.

In addition to changes in global mean climate metrics, it is also important to consider regional patterns of change; even if global mean temperature increases are constrained to within the $2^{\circ} \mathrm{C}$ target, some regions of the planet are projected to experience greater increases (e.g., Washington et al. 2009; Clark et al. 2010). The consistency of the spatial patterns of change can also have an impact upon the applicability of pattern scaling techniques (e.g., Mitchell 2003), which are a key tool in climate impact analysis.

We present new projections from the Hadley Centre Global Environmental Model, version 2 (Earth System) (HadGEM2-ES), which form a contribution to phase 5 of the Coupled Model Intercomparison Project (CMIP5) (Taylor et al. 2012). HadGEM2-ES is a state-of-the-art earth system model that includes dynamic vegetation, ocean biology, and atmospheric chemistry. HadGEM2ES has a high climate sensitivity of approximately $4.6^{\circ} \mathrm{C}$ for a doubling of $\mathrm{CO}_{2}$ that places it near the top of the range $\left(2.1^{\circ}-4.7^{\circ} \mathrm{C}\right.$ ) of the CMIP5 models (Andrews et al. 2012a). Taking into account climate change projections from models with higher sensitivity could lower the chance of a planned adaptation turning out to be inadequate, assuming that the range of model sensitivity is satisfactorily captured.

Assessments commonly consider climate projections to the year 2100, but here the projections are extended to 2300 for three of the four emissions scenarios. These extended simulations show the potential long-term implications of policy decisions and indicate whether components of the climate system, which change during the twenty-first century, stabilize beyond 2100 once the radiative forcing has become constant. For example, sea level adjusts to changes in forcing on substantially longer time scales than surface temperature because of the slow processes involved in mixing heat to the deep ocean and the long time scales for land-based ice masses to reach a new steady state (Lowe et al. 2006). These long time scales mean that it is desirable to assess the implications of any proposed mitigation measures.

\section{Scenarios and model}

Model projections featured in the Fourth Assessment Report (AR4) of the Intergovernmental Panel on Climate Change (IPCC) commonly used the future greenhouse gas emissions scenarios described in the
IPCC Special Report on Emissions Scenarios (SRES) (Nakićenović and Swart 2000). In advance of the IPCC Fifth Assessment Report (AR5), a new set of scenarios has been developed (Moss et al. 2010), with four RCPs representing a range of future climate forcing scenarios. RCP2.6 (van Vuuren et al. 2011) is the low emissions scenario (indicative radiative forcing of $2.6 \mathrm{~W} \mathrm{~m}^{-2}$ by 2100), which is comparable with previously published climate mitigation scenarios (e.g., Lowe et al. 2009). There are two midrange scenarios, RCP4.5 and RCP6.0. At the upper end is RCP8.5, which can be considered as representing a high emissions scenario (indicative radiative forcing of $8.5 \mathrm{~W} \mathrm{~m}^{-2}$ by 2100). RCP8.5 has comparable, though marginally lower, $\mathrm{CO}_{2}$ emissions to the highest of the SRES forcing scenarios (A1FI) during the twenty-first century (Raper 2012) and has been shown to produce comparable temperature projections for the twenty-first century (Rogelj et al. 2012).

HadGEM2-ES (Collins et al. 2011; Martin et al. 2011) is a coupled atmosphere-ocean GCM with interactive land and ocean carbon cycles and dynamic vegetation. The atmospheric resolution is $\mathrm{N} 96\left(1.875^{\circ} \times 1.25^{\circ}\right)$, with 38 levels in the vertical, and the ocean resolution is $1^{\circ}$ $\left(1 / 3^{\circ}\right.$ at the equator), with 40 levels in the vertical. The experimental setup followed the CMIP5 protocols (Jones et al. 2011). It has a high climate sensitivity estimated at $4.6^{\circ} \mathrm{C}$ (Andrews et al. 2012a), as already noted, and an estimated transient climate response of $2.5^{\circ} \mathrm{C}$ (Andrews et al. 2012b). The simulations comprise a historical period from 1860 to 2005 driven by historical greenhouse gases, aerosols, and natural forcings, including solar and volcanic influences, described in detail in Jones et al. (2011), with the atmospheric $\mathrm{CO}_{2}$ concentrations shown in Fig. 1a. An ensemble of four members was run for the historical period, using perturbed initial conditions.

The ends of the historical runs were used as initial conditions for the RCP simulations, with four ensemble members for each RCP being run to the year 2100 . To simulate the period from 2100 to 2300, single member extensions were run for each RCP, with the exception of RCP6.0. For RCP8.5, the atmospheric $\mathrm{CO}_{2}$ concentrations stabilize around the year 2250 at just below 2000 ppm; RCP4.5 stabilizes around the year 2150, whereas RCP2.6 shows a decline in concentrations after 2050 . We present the projections prior to 2100 as an ensemble mean of the four members based upon the good agreement between the ensemble members (see supplemental Fig. S1), with the spread between the four ensemble members generally small relative to the differences between the members forced with different emissions scenarios by the year 2100 

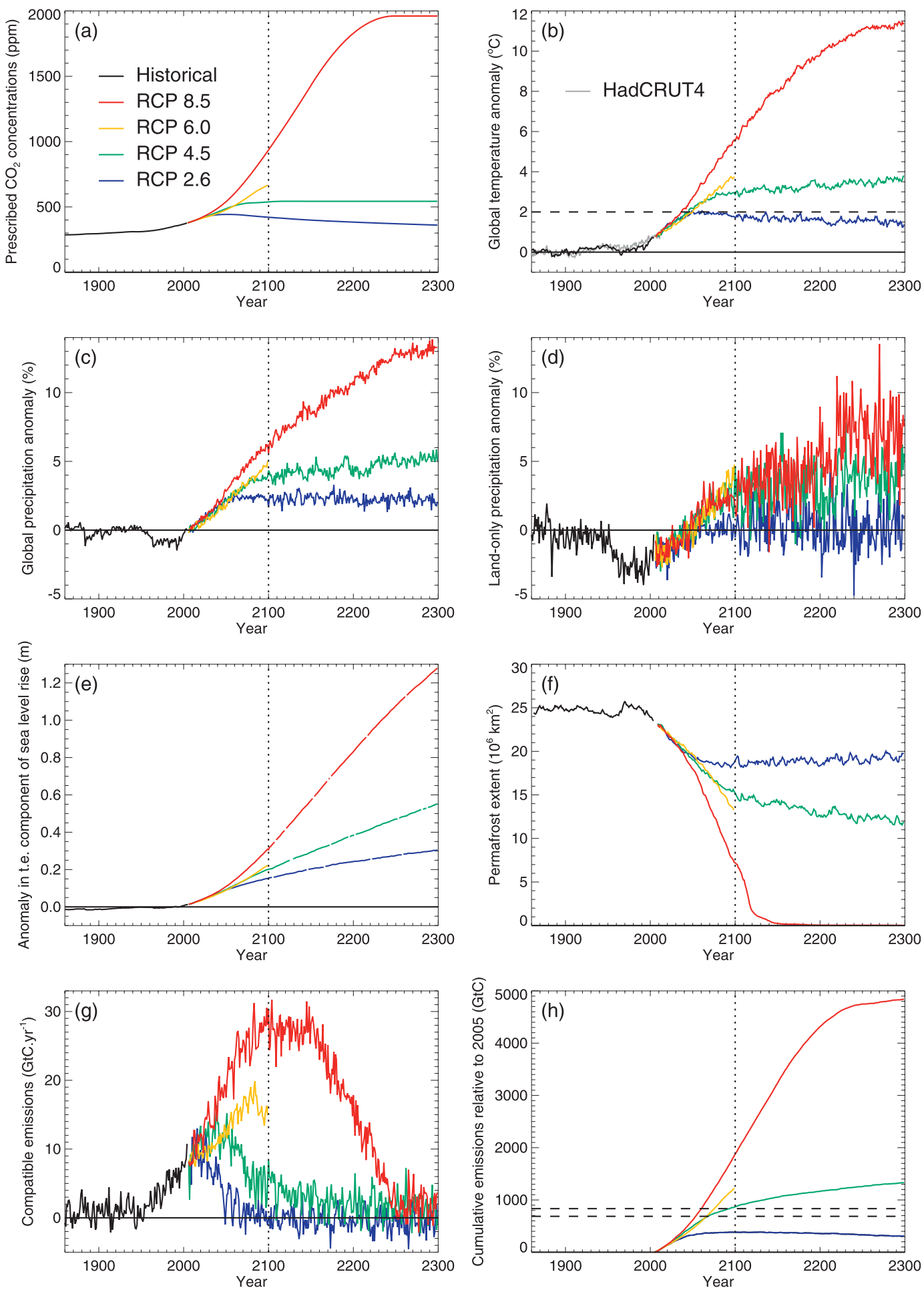

FIG. 1. Historical simulations and future projections for the RCP scenarios from 1860 to 2300 for (a) prescribed atmospheric $\mathrm{CO}_{2}$ concentrations; (b) mean global temperature anomaly relative to $1861-90$, with $2^{\circ} \mathrm{C}$ anomaly represented by the horizontal dashed line and the ensemble median HadCRUT4 (Morice et al. 2012) observational global temperature anomaly shown; (c) mean global precipitation anomaly relative to 1861-90; (d) mean global land-only precipitation anomaly relative to 1861-90; (e) thermal expansion component of sea level rise relative to 1980-99; (f) permafrost extent; (g) compatible carbon emissions; and (h) cumulative carbon emissions relative to the year 2005 with upper and lower estimates of proven fossil fuel reserves indicated by dashed lines (based upon Meinshausen et al. 2009). Up to the year 2100, the mean of the four ensemble members for each RCP is plotted. Post-2100, the single member extension is shown for each RCP, with the exception of RCP6.0, which was unavailable. Climate drift has not been adjusted for in these data. 


\section{Results}

\section{a. Temperature}

The simulations show a late-twentieth-century warming trend that began during the 1970s, in agreement with observations, and between 1976 and 2005, the ensemble mean warming in the historic simulations is $0.64^{\circ} \mathrm{C}$, compared with $0.57^{\circ} \mathrm{C}$ in the Hadley Centre/ Climatic Research Unit, version 4 (HadCRUT4), observational dataset (Morice et al. 2012). In the future, with aggressive mitigation under RCP2.6, projected global mean surface air temperature peaks during the 2040s (at a level of just over $2^{\circ} \mathrm{C}$ above preindustrial, defined here as 1861-90) and then slowly declines over the following two centuries, remaining below $2^{\circ} \mathrm{C}$ after 2100 (Fig. 1b). These changes are coincident with the gradual reductions in $\mathrm{CO}_{2}$ concentrations (cf. Fig. 1a). Under RCP4.5, the temperature anomaly increases to around $3^{\circ} \mathrm{C}$ above preindustrial during the 2070s and then increases at a slower rate to just below $4^{\circ} \mathrm{C}$ by 2300 , despite $\mathrm{CO}_{2}$ concentrations having stabilized post-2100; this is indicative of additional committed warming. The largest temperature increase occurs under RCP8.5, with the temperature anomaly rising above $2^{\circ} \mathrm{C}$ around the year 2037 and reaching nearly $6^{\circ} \mathrm{C}$ by 2100 . The temperature continues increasing and, around the midtwenty-second century, the rate of increase begins to decline, again coincident with a reduction in the rate of increase of $\mathrm{CO}_{2}$ concentrations. A global average temperature anomaly of over $11^{\circ} \mathrm{C}$ is projected by 2300 in this scenario with respect to the preindustrial period.

\section{b. Precipitation}

Under the RCP2.6 projections, global mean precipitation stabilizes around the mid-twenty-first century at just over $2 \%$ higher than preindustrial levels and continues at around this level in the extension run out to 2300 (Fig. 1c). Under RCP8.5, the precipitation anomaly increases to $6 \%$ by 2100 and continues to around $13 \%$ by 2300 . It should be noted that the largest contribution to the differences in precipitation between the RCP scenarios is made by precipitation over ocean regions, while changes over land regions (Fig. 1d) show less distinct differences. Previous studies show that global mean precipitation change is closely linked to changes in global mean temperature (e.g., Held and Soden 2006), with the relationship between changes in global mean temperature and global mean precipitation often referred to as the hydrological sensitivity (e.g., Wu et al. 2010). Figure 2 shows a broadly linear relationship between projected temperature and precipitation, up to the point where projected emissions peak and start to decline (cf. Fig. 1g), as in RCP4.5 and RCP2.6. Following this

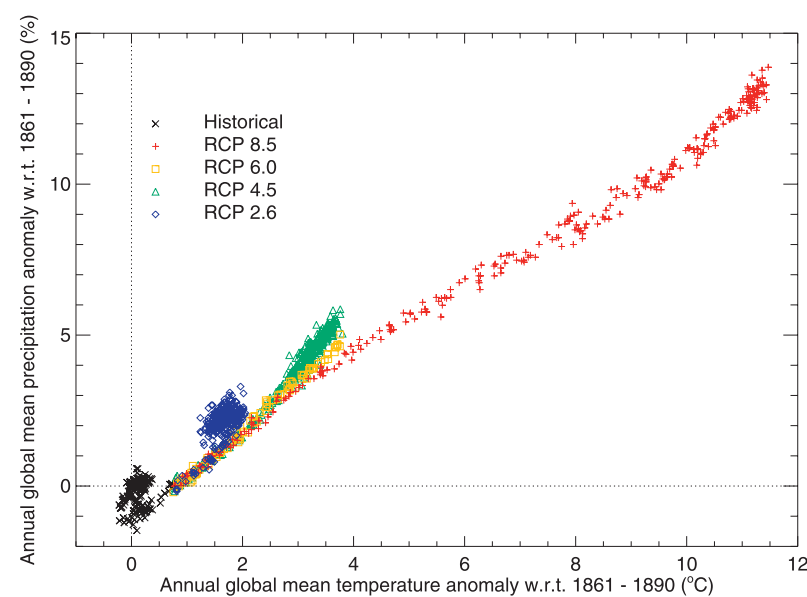

FIG. 2. Relationship between projections of annual global mean precipitation (percentage anomaly relative to 1861-90) and annual global mean temperature (anomaly relative to 1861-90). Annual values prior to 2100 are represented by the four-member ensemble mean value. Post- 2100 values are represented by the single ensemble member. Note that post-2100 values were not available for RCP6.0.

point, projected increases in precipitation occur at a faster rate compared with increases in the average global temperature. Using an idealized experiment, $\mathrm{Wu}$ et al. (2010) found that stabilizing or reducing $\mathrm{CO}_{2}$ concentrations temporarily strengthened the global hydrological cycle as a result of the inertia of accumulated heat in the oceans.

\section{c. Sea level rise (thermal expansion)}

Sea level rise projections include a component from thermal expansion of the warming ocean and a component from the addition of water from melting of land-based ice masses, primarily glaciers and ice caps together with the Greenland and Antarctic ice sheets. Here, we focus upon the thermal expansion component (Fig. 1e) with no correction for any underlying drift. IPCC AR4 found that this component accounts for about $70 \%$ of their twenty-first-century business-as-usual sea level rise projections (Meehl et al. 2007), although these do not include any potentially important but uncertain contributions from future acceleration of ice sheet dynamics.

Under RCP2.6, thermal expansion contributes $15 \mathrm{~cm}$ to the projected sea level over the twenty-first century (from 1980-99 to 2090-99). This is very close to the amount found for the GCM projections of Pardaens et al. (2011) and Washington et al. (2009) under similar mitigation scenarios [note that one of the two models used for the sea level rise projections of Pardaens et al. (2011) is the Atmosphere and Ocean (non-Earth System version) configuration of HadGEM2 (HadGEM2-AO)]. 
At the end of the twenty-first century, thermal expansion for RCP2.6 is increasing at a rate of about $1.3 \mathrm{~mm} \mathrm{yr}^{-1}$, in contrast to the by-then decreasing trend of surface temperature. Expansion under RCP 2.6 reaches $30 \mathrm{~cm}$ by 2300 (i.e., the period covering 2290-99, with respect to 1980-99), at which point the rate of increase is still positive at around $0.8 \mathrm{~mm} \mathrm{yr}^{-1}$. This continued expansion illustrates the importance of the commitment to sea level rise, which is imposed during the increase in forcing, and the long time scales over which this is realized.

For the other RCP scenarios, the contribution from thermal expansion during the twenty-first century is greater than that under RCP2.6, reaching around 19,21, and $29 \mathrm{~cm}$ for RCP4.5, RCP6.0, and RCP8.5, respectively, by 2100 . About half of the twenty-first-century expansion realized under the RCP8.5 scenario is avoided with the RCP2.6 scenario. In subsequent centuries, the avoided expansion increases, with around three quarters avoided by RCP2.6 relative to RCP 8.5 over the full 2000-2300 period and around half avoided relative to RCP4.5. By 2300, the thermal expansion component under RCP4.5 and RCP8.5 reaches 54 and $126 \mathrm{~cm}$, respectively, and nearly a meter of this component of sea level rise has been avoided by RCP 2.6 relative to RCP8.5.

\section{d. Permafrost}

Large amounts of organic carbon are stored in permanently frozen high-latitude soil. Degradation or thaw of near-surface permafrost as a result of climate change may result in a large source of carbon to the atmosphere. HadGEM2-ES does not include the feedback from thawing permafrost on the carbon cycle and the global temperature but can be used to give an estimate of the permafrost-affected area (Dankers et al. 2011). Model grid cells that have temperatures below freezing at a depth of $3 \mathrm{~m}$ for the previous 2 years are assumed to have permafrost in that grid cell. Figure 1f shows that HadGEM2-ES slightly overestimates the permafrost area in the present day, with $\sim 25$ million $\mathrm{km}^{2}$ of permafrost compared with the observed area of under 23 million $\mathrm{km}^{2}$. There are signs that this extent decreases slightly during the last 20 years of the twentieth century. This decline continues at a rate that is independent of a scenario until around 2035, then decreases more rapidly for the higher-concentration pathways than the lower ones. By 2100 there is a loss of between $30 \%$ and $60 \%$, which is slightly less than that projected by Lawrence and Slater (2008). The CMIP5 models show a wide range of present-day permafrost areas ranging from 1.4 to 27.4 million $\mathrm{km}^{2}$. Predictions for permafrost loss from 2005 to 2100 are also varied: $15 \%-87 \%$ under RCP 4.5 and 30\%-99\% under RCP8.5 (Koven et al. 2013). The extension of RCP8.5 suggests a permafrost-free Arctic by 2150 . The extensions of RCP4.5 and RCP2.6 show a relatively stable permafrost extent between 2100 and 2300 , in line with the global mean temperature.

\section{e. Compatible emissions}

In these experiments, HadGEM2-ES is driven with a time series of changing greenhouse gas concentrations. However, it is possible to derive the compatible $\mathrm{CO}_{2}$ emissions from the carbon balance of the model (Arora et al. 2011). Figure 1g shows the emissions from the historical and future simulations (discussed in more detail in Liddicoat et al. 2013). In the historical period (1860-2005), the compatible emissions closely match observation-based estimates of $\mathrm{CO}_{2}$ emissions from fossil fuel burning and industry. Under the RCPs (post2005), the compatible emissions compare well with the integrated assessment model emissions scenarios from which the concentration pathways were derived (Liddicoat et al. 2013).

Under the RCP8.5 scenario, emissions increase from $\sim 8 \mathrm{GtC} \mathrm{yr}^{-1}$ in 2005 to almost $30 \mathrm{GtC} \mathrm{yr}^{-1}$ by 2100 and then decline rapidly, stabilizing at $\sim 3 \mathrm{GtC} \mathrm{yr}^{-1}$ by 2250 . The two lower emissions scenarios lead to declining emissions by the end of the twenty-first century, with RCP2.6 emissions peaking early in the twenty-first century at $\sim 13 \mathrm{GtC} \mathrm{yr}^{-1}$.

The compatible emissions exhibit strong variability since they are determined from land carbon uptake, which varies considerably from year to year, as well as ocean carbon uptake and changes in atmospheric $\mathrm{CO}_{2}$. Therefore, occasional years of negative emissions are evident in RCP2.6 toward the end of the twenty-first century, but it is not until 2100 that net negative emissions become necessary to adhere to the $\mathrm{CO}_{2}$ concentration pathway, remaining so over much of the following two centuries.

Meinshausen et al. (2009) reviewed estimates of potential total emissions from burning all proven fossil fuel reserves (i.e., those that are economically recoverable assuming current technology and prices) and derived a midrange estimate of $2800 \mathrm{GtCO}_{2}$. Converting this gives a median value of $764 \mathrm{GtC}$, and converting the 10th and 90th percentile range estimates provides a range of 687-834 GtC. In the experiments presented here, the median estimate is reached by the mid-twentyfirst century under RCP8.5 and the late twenty-first century under RCP6.0 and RCP4.5 (Fig. 1h). Fossil fuel resource limitations may need to be considered in relation to future emissions scenarios (Vernon et al. 2011), since this issue could affect future choices of energy technology. It should be noted that unconventional fossil fuel resources, such as tar sands and oil shale, are 
(a)

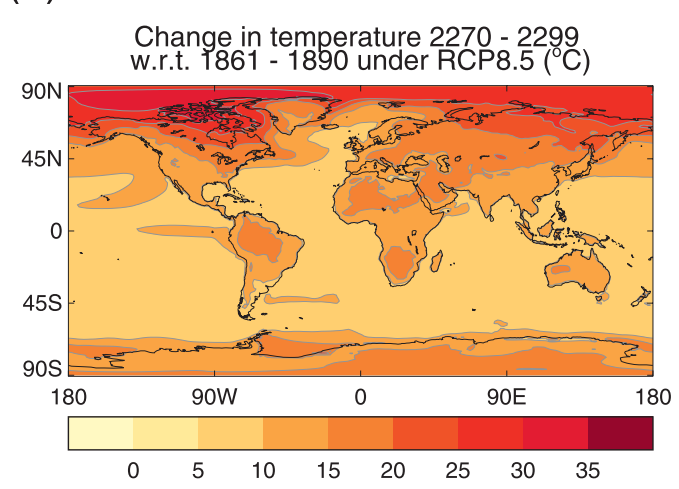

(b)

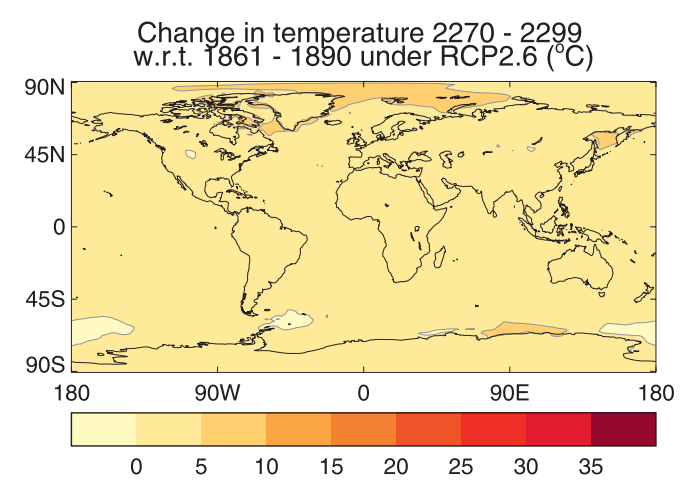

(c)

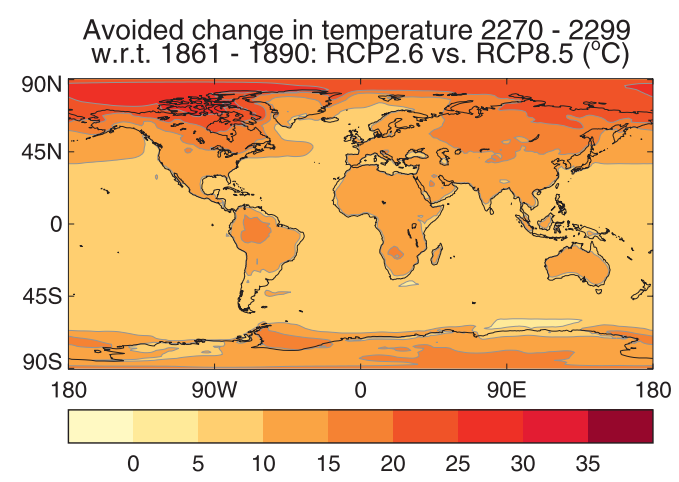

(d)

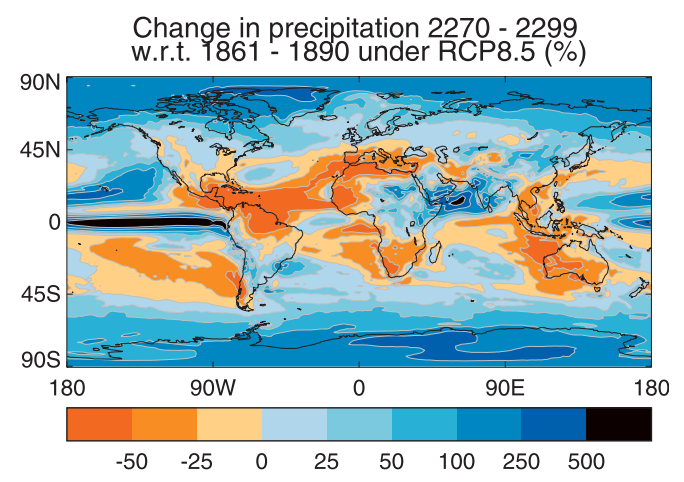

(e)

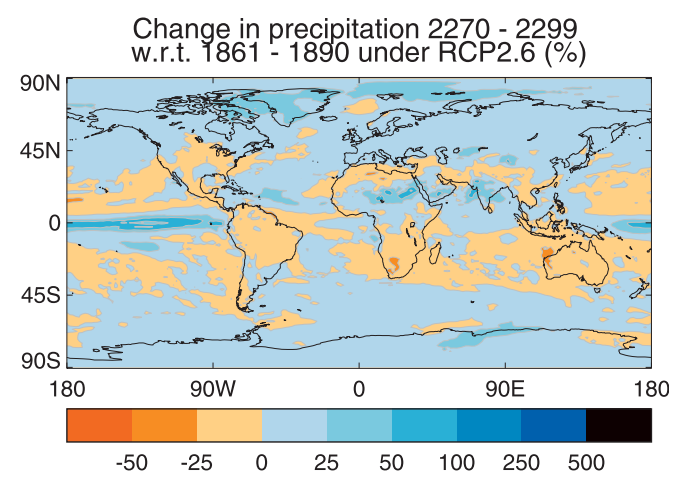

(f)

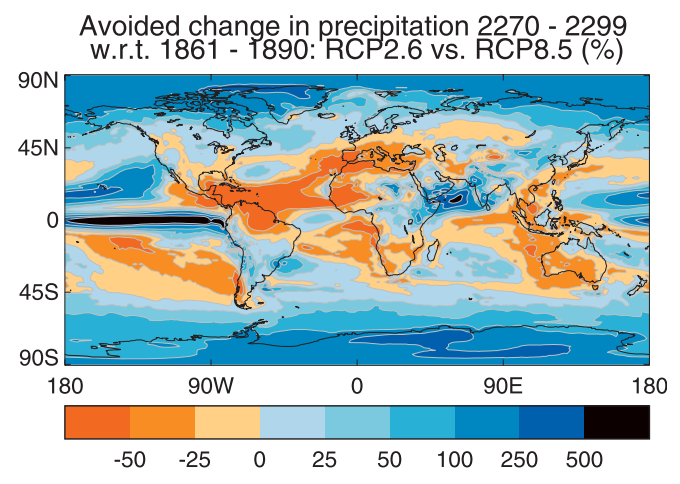

FIG. 3. Projected changes in (a),(b) temperature and (d),(e) precipitation between 1861-90 and 2270-99 under the RCP8.5 and RCP2.6 scenarios. (c),(f) Avoided changes (difference between RCP8.5 and RCP2.6) are also shown.

estimated to be many times larger than proven reserves based upon current prices and technology and that there remain large uncertainties in estimates of reserves and resources and the potential future costs of recovery.

\section{f. Regional changes of temperature and precipitation}

Figure 3 shows the projected changes in temperature and precipitation by 2300 under the RCP 8.5 and RCP 2.6 pathways and the avoided changes represented by the differences between these two RCPs at 2300. Changes in both temperature and precipitation are generally larger in magnitude under RCP8.5 than RCP2.6. Projected temperature increases tend to be larger at higher latitudes and over land regions. Evaluating differences at the grid point level indicates that most grid point changes are significant at the 5\% level (based upon a Student's $t$ test) for temperature in both RCP8.5 and $\mathrm{RCP} 2.6$ projections. The patterns of change are relatively consistent between the different RCPs, and temperature is projected to increase more than the global 
(a)

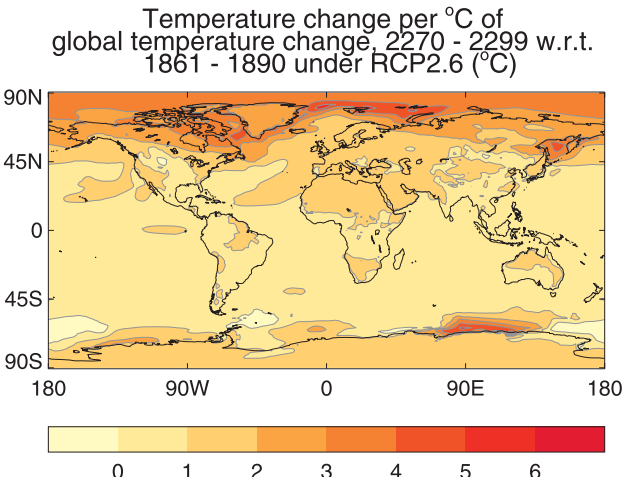

(c)
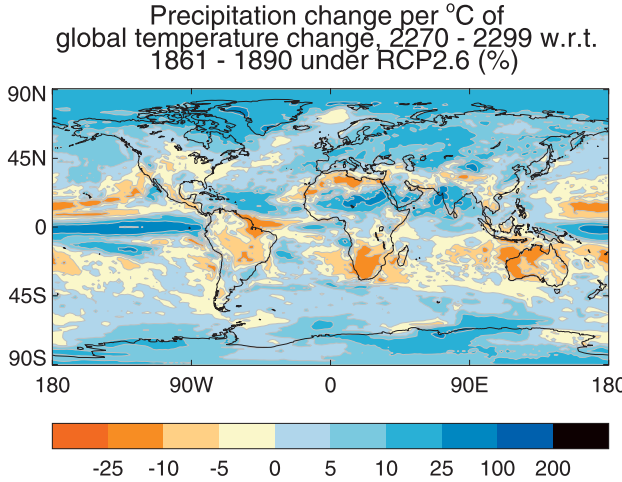

(b) Temperature change per ${ }^{\circ} \mathrm{C}$ of

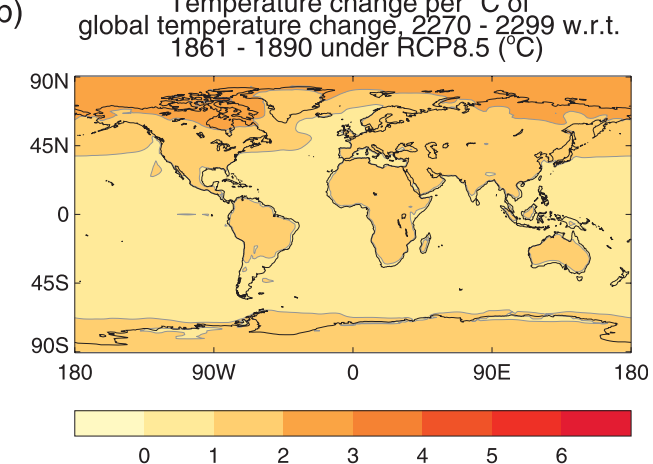

(d)

Precipitation change per ${ }^{\circ} \mathrm{C}$ of global temperature change, $2270-2299$ w.r.t. $1861-1890$ under RCP 8.5 (\%)

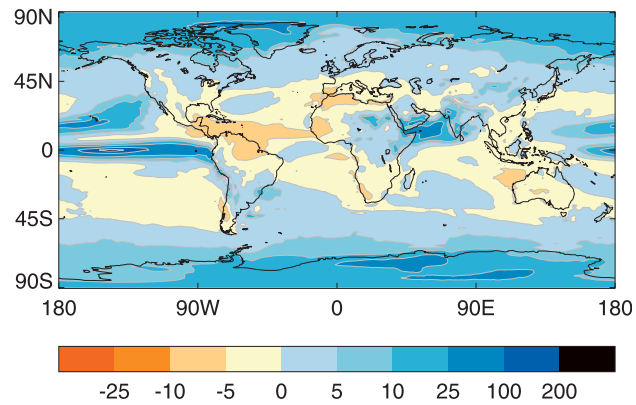

FIG. 4. Projected (a),(b) temperature and (c),(d) precipitation changes per unit change in global temperature for RCP2.6 and RCP8.5 for 2270-99 relative to 1861-90.

mean over land and in high-latitude regions, particularly in the Arctic (Figs. 4a,b). Under RCP8.5, most land regions are projected to experience changes of over $6^{\circ} \mathrm{C}$ compared with preindustrial by 2100 , with changes of $10^{\circ}-20^{\circ} \mathrm{C}$ in the northern high latitudes (see supplemental Fig. S2). Under RCP2.6, projected changes are much smaller, with typical increases of $1^{\circ}-2^{\circ} \mathrm{C}$ over most land regions and $6^{\circ}-8^{\circ} \mathrm{C}$ in the northern high latitudes. By 2300 changes of over $10^{\circ} \mathrm{C}$ are avoided in many regions for the RCP2.6 pathway (Fig. 3c).

Precipitation shows projected increases over many areas of the world under RCP8.5 by 2300 (Fig. 3d), with most regions displaying significant changes except for the regions of smaller changes marking the transition between regions becoming wetter and those becoming drier. The large-scale patterns of change are generally similar under RCP2.6, though with a reduced magnitude, and there are fewer regions with significant changes, which include the regions of increasing precipitation over the equatorial Pacific Ocean, southern Asia, North Africa, and much of northern Europe and Russia. Regions with a significant projected decrease in precipitation include northern South America, southern Africa, and parts of western and northern Australia, with reductions of over $25 \%$ projected over some of these regions by 2300 . Regional changes in precipitation can be a result of a number of mechanisms, including circulation changes or thermodynamic factors, but the large-scale patterns of change seen in these simulations are consistent with other studies (e.g., Meehl et al. 2007), with generally increasing precipitation in the tropics and decreasing precipitation in the subtropics.

Precipitation changes with respect to global mean temperature changes (Figs. $4 \mathrm{c}, \mathrm{d}$ ) are much more spatially variable than temperature changes, and there are relatively consistent spatial patterns between the high and low RCPs, though with some local differences, such as the direction of the precipitation changing over southern Europe (this is a consistent difference across all four ensemble members of each RCP).

The change in the intensity of heat waves was examined using a simple metric (mean temperature of the warmest three consecutive nights in a year), as used by Washington et al. (2009). The change in this metric between 1861-90 and 2090-99 is shown for the high and low emissions scenarios of RCP8.5 and RCP2.6, along with the avoided changes (Fig. 5). Heat waves are projected to become more intense in the future, especially under the RCP8.5 scenario. An increase in intensity of over $4^{\circ} \mathrm{C}$ is avoided over most land areas, and $2^{\circ} \mathrm{C}$ is 
(a)

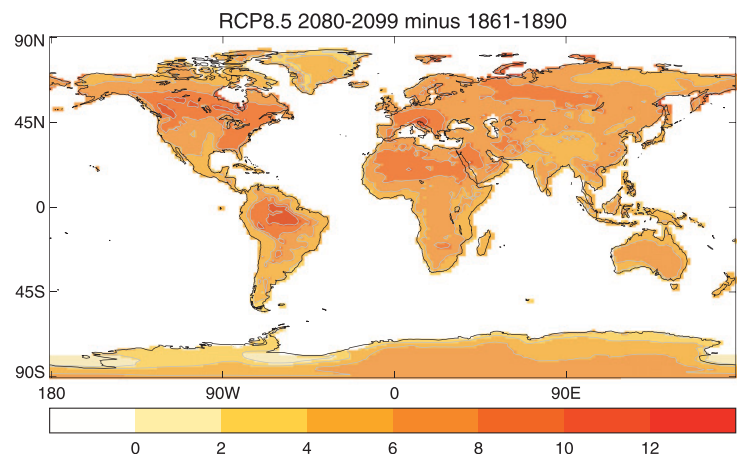

(b)

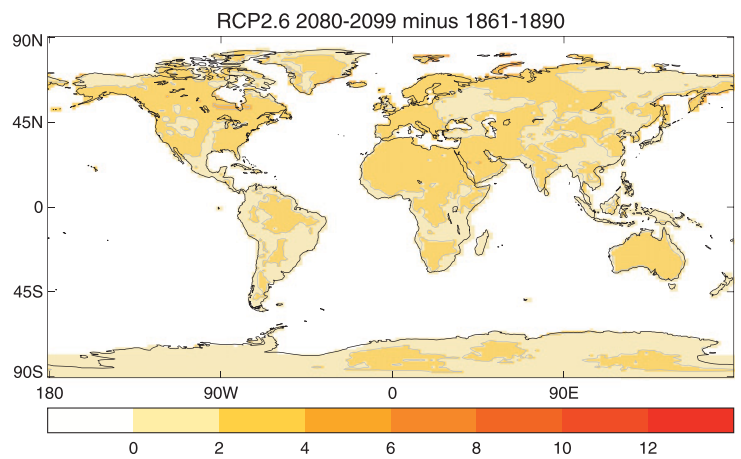

(c)

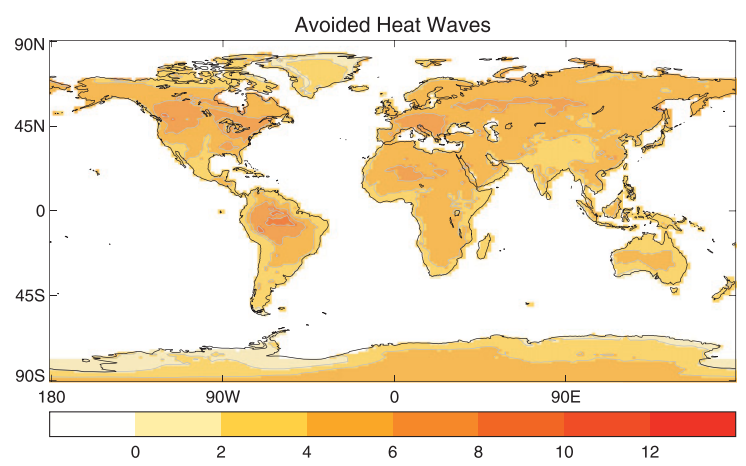

FIG. 5. Projected ensemble mean changes in heat waves between 1861-90 and 2080-99, as represented by the mean temperature of the warmest three consecutive nights in a year: (a) RCP8.5, (b) RCP2.6, and (c) avoided changes.

avoided over much of the remaining areas with mitigation. Projected increases in heat wave intensity out to 2300 under RCP8.5 reach above $24^{\circ} \mathrm{C}$ over parts of the globe with potential avoided changes of a similar magnitude (see supplemental Fig. S3).

\section{Summary and discussion}

Under the RCP2.6 mitigation scenario, atmospheric $\mathrm{CO}_{2}$ concentrations peak in the mid-twenty-first century and then slowly decline, with projected compatible emissions declining to around zero by 2100 . Global mean temperature anomalies are projected to slightly exceed $2^{\circ} \mathrm{C}$, then stabilize at just below $2^{\circ} \mathrm{C}$ beyond the mid-twenty-first century. RCP2.6 is the only one of the RCP scenarios that is approximately consistent with achieving a global mean temperature change of less than $2^{\circ} \mathrm{C}$, though this limit is exceeded in these projections during the peak in temperatures in the mid-twenty-first century. In comparison with other GCM studies that have used RCP2.6, Meehl et al. (2012) found that the CCSM4.0 model projected an end of twenty-first-century anomaly of $1.83^{\circ} \mathrm{C}$ above preindustrial, whereas Arora et al. (2011), using the CanESM2 model, projected an anomaly of $2.3^{\circ} \mathrm{C}$. This may in part be related to differences in climate sensitivity between the models, with CCSM4.0 having a lower equilibrium climate sensitivity of $3.2^{\circ} \mathrm{C}$ (Meehl et al. 2012; Bitz et al. 2012) compared with $3.7^{\circ} \mathrm{C}$ for CanESM2 and $4.6^{\circ} \mathrm{C}$ for HadGEM2-ES (Andrews et al. 2012a). Despite the global mean change of around $2^{\circ} \mathrm{C}$ under RCP2.6, there will be regions where local changes in temperature exceed $2^{\circ} \mathrm{C}$, such as over land regions and at northern high latitudes. Mitigation could also drastically reduce the intensity of future heat waves, with associated health benefits (e.g., Gosling et al. 2009). Given the large projected increases in temperatures (and extreme temperatures) over some regions, future work should question how suitable today's climate models are for representing such large changes in surface warming.

A projected loss of permafrost of between $30 \%$ and $60 \%$ by 2100 may release significant amounts of old carbon into the atmosphere and have a positive feedback on global temperatures (Schuur et al. 2008), though permafrost carbon dynamics are not currently represented in the model. This additional carbon flux would reduce the allowable emissions required to reach a specified global mean temperature. Despite peak emissions under RCP8.5 occurring around the year 2100, atmospheric $\mathrm{CO}_{2}$ concentrations continue to rise into the twenty-third century, and global mean temperature is projected to continue rising by 2300 . While the permafrost release in these scenarios represents an amplifying factor to climate change, the release is not expected to manifest as an abrupt threshold event.

The thermal expansion component of sea level rise (i.e., excluding input from changing glaciers or ice sheets) in these HadGEM2-ES simulations is projected to increase by around $29 \mathrm{~cm}$ by 2100 under RCP 8.5 , with a continued increase to $126 \mathrm{~cm}$ by 2300 . Under RCP2.6, the contribution to 2100 is only $15 \mathrm{~cm}$, that is, avoiding around half of the rise projected under RCP8.5. However, even under RCP2.6 there remains a gradual increasing trend, which reaches $30 \mathrm{~cm}$ by the year 2300 despite declining surface temperatures. The twenty-firstcentury projections of thermal expansion and surface 
temperature under the RCP2.6 and RCP6.0 scenarios are similar to those under the E1 and A1B-Integrated Model to Assess the Global Environment (A1B-IMAGE) scenarios in the study of Pardaens et al. (2011). Yin (2012) analyzed the thermal expansion components from an ensemble of CMIP5 models and found ensemble mean increases of 13,18 , and $28 \mathrm{~cm}$ in RCP2.6, 4.5, and 8.5 , respectively, by 2100 relative to 2006 . The ensemble standard deviation on these values was $\pm 3 \mathrm{~cm}$. For an ensemble of projections to 2300 , the increases were $21 \pm 5 \mathrm{~cm}$ for RCP2.6, $52 \pm 10 \mathrm{~cm}$ for RCP4.5, and $119 \pm 15 \mathrm{~cm}$ for RCP8.5. The gradual and continued increase beyond the twenty-first century in RCP2.6 shows that there may be an ongoing long-term commitment to sea level rise, even if aggressive mitigation policies are enacted. The nonlinear relationship between near-surface atmospheric temperature increase and thermal expansion illustrates why choosing a global temperature limit might not be appropriate if one is primarily concerned about coastal flooding impacts.

An aggressive mitigation approach, represented here by RCP2.6, could contribute to avoiding the larger magnitude climate changes and impacts projected under higher emissions scenarios. Despite these benefits, changes should still be expected under an aggressive mitigation pathway, and adaptation may still be required.

Acknowledgments. This work was supported by the Joint Department of Energy and Climate Change (DECC)/Department for Environment, Food, and Rural Affairs (DEFRA) Met Office Hadley Centre Climate Programme (GA01101).

\section{REFERENCES}

Andrews, T., J. M. Gregory, M. J. Webb, and K. E. Taylor, 2012a: Forcing, feedbacks and climate sensitivity in CMIP5 coupled atmosphere-ocean climate models. Geophys. Res. Lett., 39, L09712, doi:10.1029/2012GL051607.

_ M. A. Ringer, M. Doutriaux-Boucher, M. J. Webb, and W. J. Collins, 2012b: Sensitivity of an Earth system climate model to idealized radiative forcing. Geophys. Res. Lett., 39, L10702, doi:10.1029/2012GL051942.

Arora, V. K., and Coauthors, 2011: Carbon emission limits required to satisfy future representative concentration pathways of greenhouse gases. Geophys. Res. Lett., 38, L05805, doi:10.1029/2010GL046270.

Bitz, C. M., K. M. Shell, P. R. Gent, D. A. Bailey, G. Danabasoglu, K. C. Armour, M. M. Holland, and J. T. Kiehl, 2012: Climate sensitivity of the Community Climate System Model, version 4. J. Climate, 25, 3053-3070.

Clark, R. T., J. M. Murphy, and S. J. Brown, 2010: Do global warming targets limit heatwave risk? Geophys. Res. Lett., 37, L17703, doi:10.1029/2010GL043898.

Collins, W. J., and Coauthors, 2011: Development and evaluation of an Earth-system model-HadGEM2. Geosci. Model Dev., 4, 1051-1075, doi:10.5194/gmd-4-1051-2011.
Dankers, R., E. J. Burke, and J. Price, 2011: Simulation of permafrost and seasonal thaw depth in the JULES land surface scheme. Cryosphere, 5, 773-790, doi:10.5194/tc-5-773-2011.

Gosling, S. N., J. A. Lowe, G. R. McGregor, M. Pelling, and B. D. Malamud, 2009: Associations between elevated atmospheric temperature and human mortality: A critical review of the literature. Climatic Change, 92, 299-341.

Held, I. M., and B. J. Soden, 2006: Robust responses of the hydrological cycle to global warming. J. Climate, 19, 5686-5699.

Johns, T. C., and Coauthors, 2011: Climate change under aggressive mitigation: The ENSEMBLES multi-model experiment. Climate Dyn., 37, 1975-2003, doi:10.1007/s00382-011-1005-5.

Jones, C. D., and Coauthors, 2011: The HadGEM2-ES implementation of CMIP5 centennial simulations. Geosci. Model Dev., 4, 543-570, doi:10.5194/gmd-4-543-2011.

Koven, C. D., W. J. Riley, and A. Stern, 2013: Analysis of permafrost thermal dynamics and response to climate change in the CMIP5 earth system models, J. Climate, 26, 1877-1900.

Lawrence, D. M., and A. G. Slater, 2008: Incorporating organic soil into a global climate model. Climate Dyn., 30, 145-160, doi:10.1007/s00382-007-0278-1.

Liddicoat, S. K., C. D. Jones, and E. Robertson, 2013: $\mathrm{CO}_{2}$ emissions determined by HadGEM2-ES to be compatible with the Representative Concentration Pathway scenarios and their extensions. J. Climate, in press.

Lowe, J. A., J. M. Gregory, J. Ridley, P. Huybrechts, R. J. Nicholls, and M. Collins, 2006: The role of sea-level rise and the Greenland ice sheet in dangerous climate change: Implications for the stabilisation of climate. Avoiding Dangerous Climate Change, H.-J. Schellnhuber et al., Eds., Cambridge University Press, 29-36.

- C. D. Hewitt, D. P. van Vuuren, T. C. Johns, E. Stehfest, J.-F. Royer, and P. J. van der Linden, 2009: New study for climate modeling, analyses, and scenarios. Eos, Trans. Amer. Geophys. Union, 90, 181-182, doi:10.1029/2009EO210001.

Martin, G. M., and Coauthors, 2011: The HadGEM2 family of Met Office Unified Model Climate configurations. Geosci. Model Dev., 4, 723-757, doi:10.5194/gmd-4-723-2011.

Meehl, G. A., and Coauthors, 2007: Global climate projections. Climate Change 2007: The Physical Science Basis, S. Solomon et al., Eds., Cambridge University Press, 847-940.

, and Coauthors, 2012: Climate system response to external forcings and climate change projections in CCSM4. J. Climate, 25, 3661-3683.

Meinshausen, M., N. Meinshausen, W. Hare, S. C. B. Raper, K. Frieler, R. Knutti, D. J. Frame, and M. R. Allen, 2009: Greenhouse-gas emission targets for limiting global warming to $2^{\circ} \mathrm{C}$. Nature, $\mathbf{4 5 8}, 1158-1162$, doi:10.1038/nature 08017 .

Mitchell, T. D., 2003: Pattern scaling: An examination of the accuracy of the technique for describing future climates. Climatic Change, 60, 217-242.

Morice, C. P., J. J. Kennedy, N. A. Rayner, and P. D. Jones, 2012: Quantifying uncertainties in global and regional temperature change using an ensemble of observational estimates: The HadCRUT4 dataset. J. Geophys. Res., 117, D08101, doi:10.1029/ 2011JD017187.

Moss, R. H., and Coauthors, 2010: The next generation of scenarios for climate change research and assessment. Nature, 463, 747756.

Nakićenović, N., and R. Swart, Eds., 2000: Special Report on Emissions Scenarios. Cambridge University Press, 600 pp.

Pardaens, A. K., J. A. Lowe, S. Brown, R. J. Nicholls, and D. de Gusmão, 2011: Sea-level rise and impacts projections under 
a future scenario with large greenhouse gas emission reductions. Geophys. Res. Lett., 38, L12604, doi:10.1029/2011GL047678.

Raper, S., 2012: Climate modelling: IPCC gazes into the future. Nat. Climate Change, 2, 232-233, doi:10.1038/nclimate1467.

Rogelj, J., M. Meinshausen, and R. Knutti, 2012: Global warming under old and new scenarios using IPCC climate sensitivity range estimates. Nat. Climate Change, 2, 248-253, doi:10.1038/ nclimate1385.

Schuur, E. A. G., and Coauthors, 2008: Vulnerability of permafrost carbon to climate change: Implications for the global carbon cycle. Bioscience, 58, 701-714, doi:10.1641/B580807.

Taylor, K. E., R. J. Stouffer, and G. A. Meehl, 2012: An Overview of CMIP5 and the experiment design. Bull. Amer. Meteor. Soc., 93, 485-498.

UNFCCC, 2011: Establishment of an ad hoc working group on the Durban Platform for Enhanced Action. Doc. FCCC/CP/2011/ L.10, 2 pp. [Available online at http://unfccc.int/resource/docs/ 2011/cop17/eng/110.pdf.] van Vuuren, D. P., and Coauthors, 2011: RCP2.6: Exploring the possibility to keep global mean temperature increase below $2^{\circ}$ C. Climatic Change, 109, 95-116, doi:10.1007/s10584-0110152-3.

Vernon, C., E. Thompson, and S. Cornell, 2011: Carbon dioxide emission scenarios: Limitations of the fossil fuel resource. Procedia Environ. Sci., 6, 206-215.

Washington, W. M., R. Knutti, G. A. Meehl, H. Teng, C. Tebaldi, D. Lawrence, L. Buja, and W. G. Strand, 2009: How much climate change can be avoided by mitigation? Geophys. Res. Lett., 36, L08703, doi:10.1029/2008GL037074.

Wu, P., R. Wood, J. Ridley, and J. Lowe, 2010: Temporary acceleration of the hydrological cycle in response to a $\mathrm{CO}_{2}$ rampdown. Geophys. Res. Lett., 37, L12705, doi:10.1029/ 2010 GL043730.

Yin, J., 2012: Century to multi-century sea level rise projections from CMIP5 models. Geophys. Res. Lett., 39, L17709, doi:10.1029/ 2012 GL052947. 